\title{
Immune Function, Body Size, and Parasite Load in Lubber Grasshoppers
}

\author{
Alex Kreuzer, Jinger Walrath, Meaghan Hirsch and Olcay Akman \\ Department of Mathematics \\ Illinois State University \\ Normal, Illinois 61790 USA
}

\author{
Dori Pitynski, Jason Jannot, and Steve Juliano \\ School of Biological Sciences \\ Illinois State University \\ Normal, Illinois 61790 USA
}

Received: September 23, 2008

Accepted: December 6, 2008

\begin{abstract}
Immunity is an important biological property of organisms that protects them from parasites. Similarly, body size is one of the most important biological traits because almost all biological processes, from the cellular to the ecosystem level, scale with body size. Our goal was to determine the correlation between body size and immune function in different populations of the eastern lubber grasshopper (Romalea microptera) which differ in body size. Field data was collected on grasshopper location, size (thorax and femur lengths), and immune function (measured by melanization response). In accordance with previous work, we found a significant body size cline among populations of south Florida grasshoppers: on average, small adult grasshoppers are found in western populations whereas large grasshoppers are found in eastern populations. However, we did not find a significant relationship between body size and one measure of immune function, either within or across these populations. Future work should be directed at understanding when body size and immune function might or might not be correlated.

\section{INTRODUCTION}

Body size is an important biological variable because processes at every level of biology (molecules to ecosystems) are determined, at least in part, by scaling with body size. For example, the sizes of animal appendages (e.g., wings, legs) are determined, in part, by the overall body size of individuals. Geographic variation in body size is quite common because body size is so important in determining the biology of organisms. Understanding how size variation arises and the consequences of size variation for different populations of the same species is a central goal of ecology.

One way that body size variation can arise is through parasitism. Parasites can cause body size variation in one of two

ways. First, parasites can divert nutritional and energetic resources away from cell growth and development and toward mounting an immune response. The amount of energy available to an organism is positively scaled with body size-larger organisms have more energy. Second, susceptibility of animals to parasitism could be size-dependent, causing size-dependent patterns of mortality. For example if larger (or smaller) animals are more likely to be parasitized, then larger animals might also be more likely to die from parasitism. Such a pattern of size-dependent mortality would favor survival of small individuals relative to large and skew the average size of the population down toward smaller sizes.

We tested the first hypothesis in the eastern lubber grasshopper, Romalea
\end{abstract}




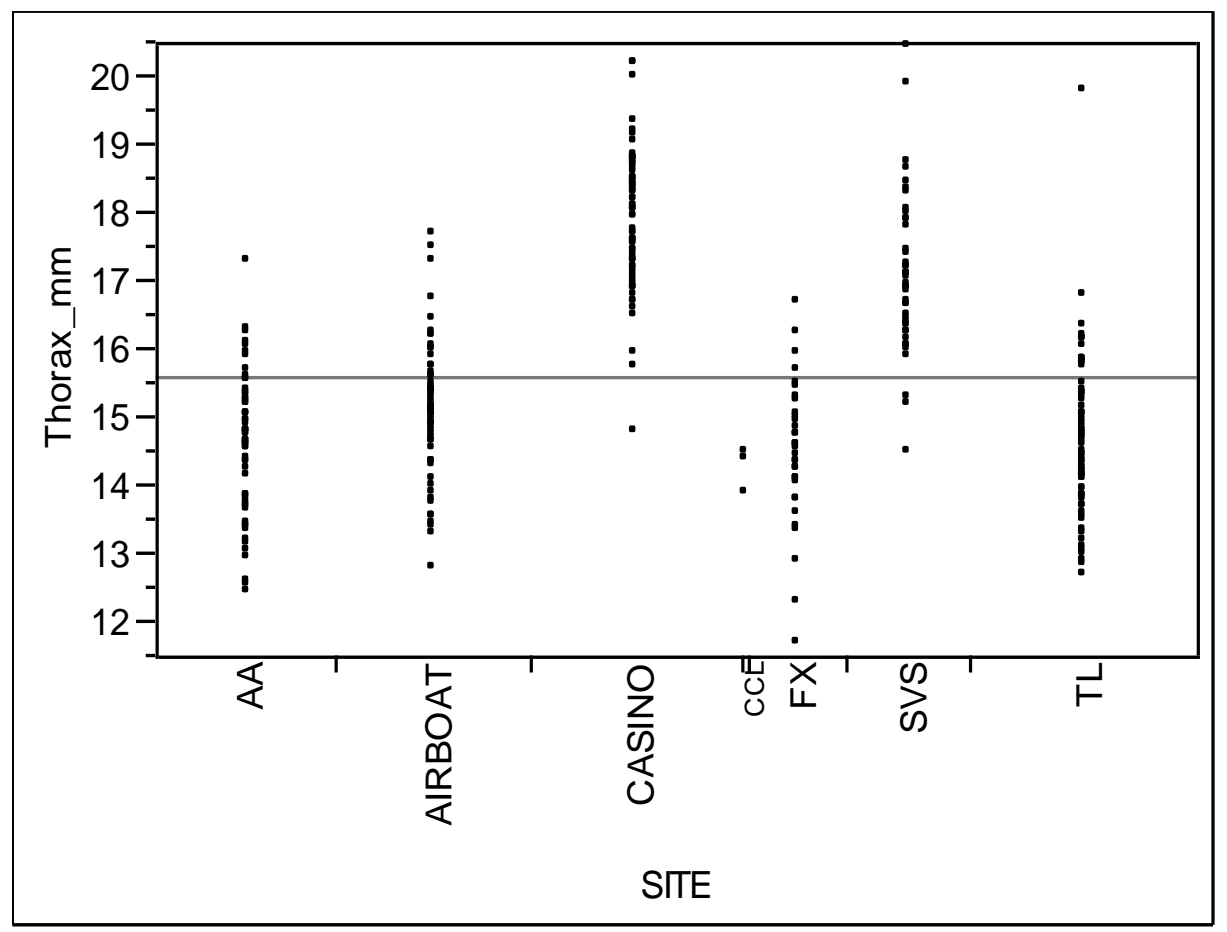

Figure 1. Thorax Size by Site.

microptera, which exhibits a cline in body size in south Florida: small adult lubbers are found in the western portion of peninsular Florida and the average body size of adult lubbers gradually increases toward the east [1]. The difference in average adult size between the western-most population and the eastern-most population is about $30 \%$. We anticipated that immunocompetence might play a role in the adult body size cline. Immunocompetence requires energy to create immune cells and mobilize an immune response. We predict that small grasshoppers will have less energy available than large grasshoppers, and therefore, small grasshoppers will have a lower immunocompetence than large grasshoppers.

\section{METHODS}

The data utilized for this research project was collected from six sites in the Greater Everglades Ecosystem, Florida. The six sites were located along U.S. route 41 (aka Tamiami Trail) and Florida state route 29, formed the west-east size cline of body size, and were named, in order from west to east: Ally Auto $(=A A)$, Fakanhatchee
Strand $=(F X)$, Trail Lakes $(=T L)$, Airboat, Shark Valley South (=SVS), and Casino. We visited these sites for five weeks collecting only male lubber grasshoppers. Grasshoppers were gathered by handcapturing every fifth individual until we obtained 30 males. Two measures of size were taken, length of the thorax and femur, using digital calipers.

Grasshoppers were returned to the field laboratory in south Florida to test for immunocompetence by the melanization technique. To reduce activity levels and potential for injury, each grasshopper was chilled for 15 minutes prior to inserting a 6 $\mathrm{mm}$ long piece of nylon fishing line rubbed with sand paper between the first and second abdominal segments. Each grasshopper was then placed in an individual plastic container $(\sim 946 \mathrm{ml})$ at room temp for 24 hours. Nylon implants removed and photographed under a dissecting microscope along with a nylon line of similar size that was not implanted into a grasshopper. The unimplanted line was used as a baseline control for quantifying the amount of melanization. Photographs were evaluated using the image-processing program, Image J. The 


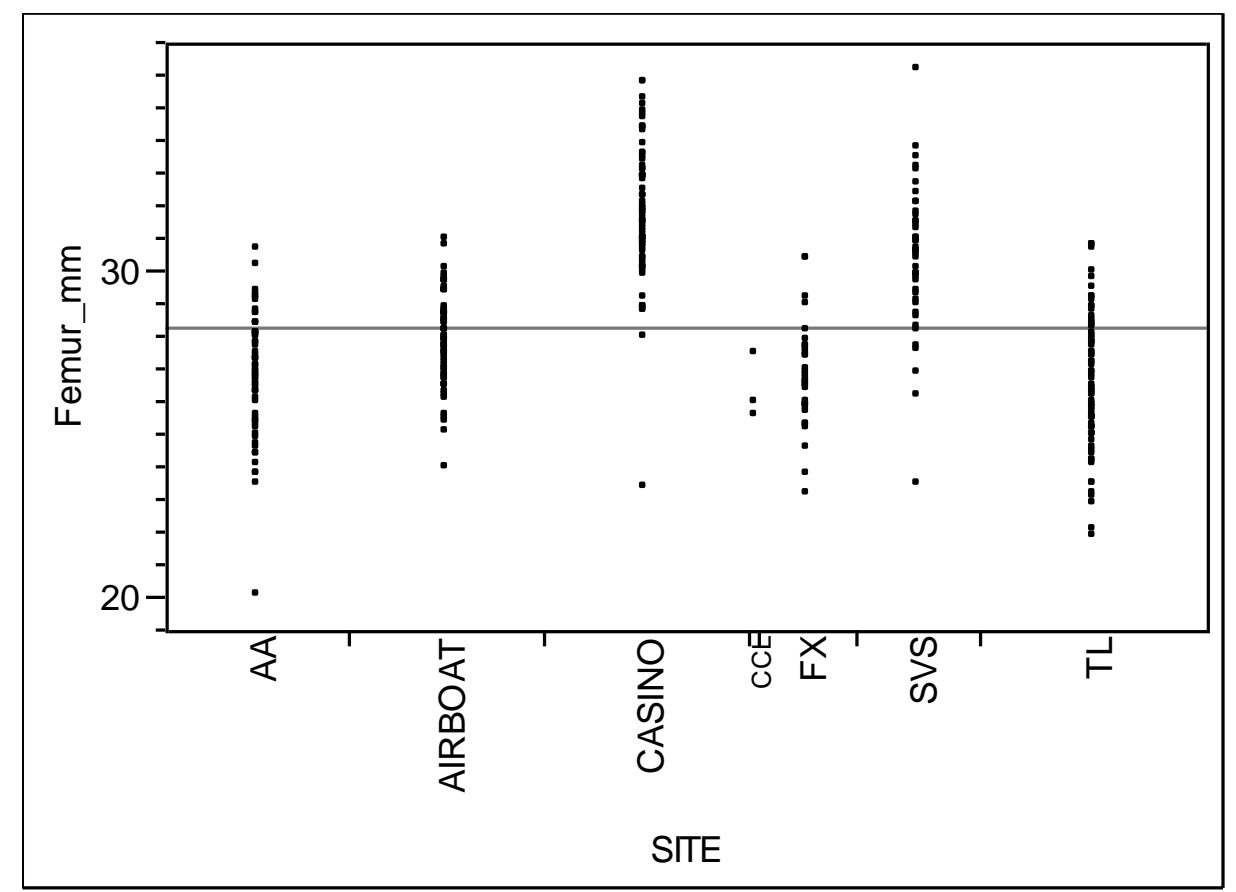

Figure 2. Femur Size by Site.

middle portion of the line was selected for analysis and a histogram of that area was produced. The histogram breaks down the shades of grey into 256 shades and then shows the percentage of each shade in the form of a graph. The darker the filament the more melanization and therefore, the more the immune system reacted.

\section{RESULTS}

The grasshoppers' sizes varied from site to site. The grasshoppers from Casino and SVS have the similar ranges as shown in Figure 1 and Figure 2. On the other hand the grasshoppers from sites AA, Airboat, FX, and $T L$ have similar ranges as shown in Figures 1 and 2.

The average size of the grasshoppers increases as the sites move from west to east (Tables 1 and 2). The grasshoppers' immune system may be influencing the grasshoppers' sizes. Figures 3 and 4 show the size of the grasshoppers by the effectiveness of the grasshoppers' immune system. We determined any sized grasshopper could have a darkened nylon string ranging from 911 pixels to 210 pixels. Since each site has different sized grasshoppers the grasshoppers' immune

\begin{tabular}{|c|c|}
\hline Site & Average Thorax Size in $\mathbf{~ m m}$ \\
\hline AA & 14.5548387 \\
\hline FX & 14.4354545 \\
\hline TL & 14.6203846 \\
\hline AIRBOAT & 15.059403 \\
\hline SVS & 17.0369767 \\
\hline CASINO & 17.8630556 \\
\hline
\end{tabular}

Table 1. Average Thorax Size

\begin{tabular}{|c|c|}
\hline Site & Average Femur Size in $\mathbf{~ m m}$ \\
\hline AA & 26.70097 \\
\hline FX & 26.66182 \\
\hline TL & 26.46923 \\
\hline AIRBOAT & 27.84522 \\
\hline SVS & 30.29093 \\
\hline CASINO & 31.69268 \\
\hline
\end{tabular}

Table 2. Average Femur Size. 


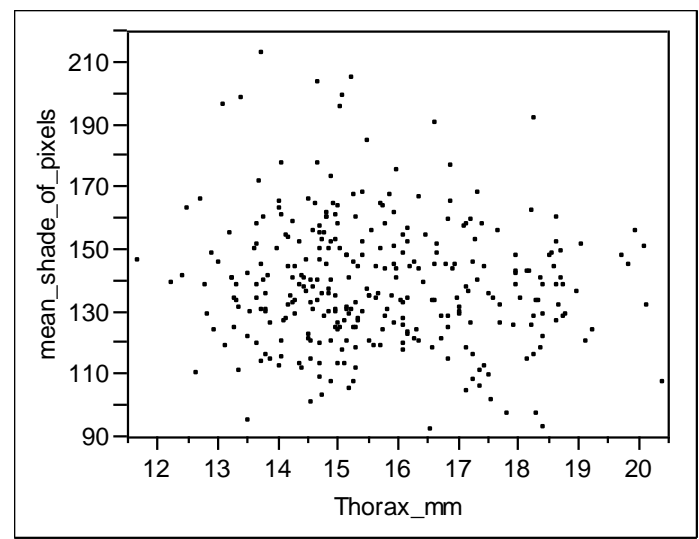

Figure 3. Mean Shade by Thorax Size.

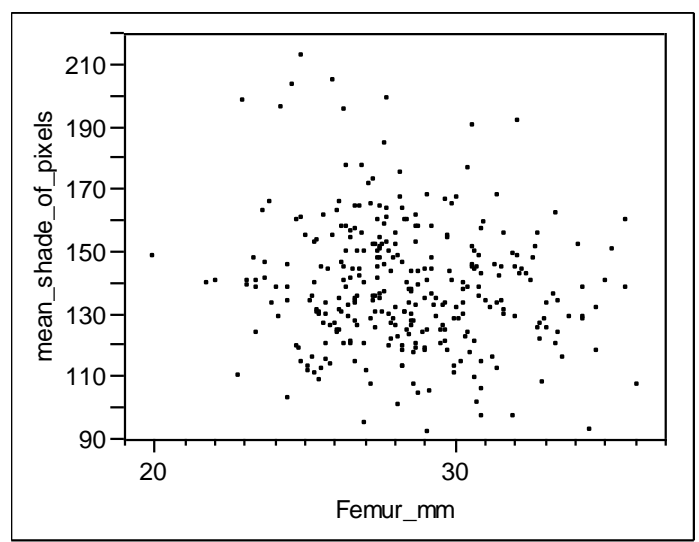

Figure 4. Mean Shade by Femur Size.

system may be related to the size of the grasshopper within each site.

We found the grasshoppers' immune system is not related to their size within each site. Figures 5 through 10 show the sizes of the thorax (a measure of size) by the power of each grasshopper's immune system within each site. Each graph shows almost no correlation between the two factors. Therefore, any size grasshopper can have a range of darkened filament.

\section{CONCLUSION}

We found that the average size of the grasshoppers increases from west to east, which confirms the pattern first observed by [1]. However, the size of the grasshoppers is not correlated with the ability of the immune system to melanize foreign objects. Therefore, the grasshopper's body size does not influence the grasshoppers' ability to reject maggots.

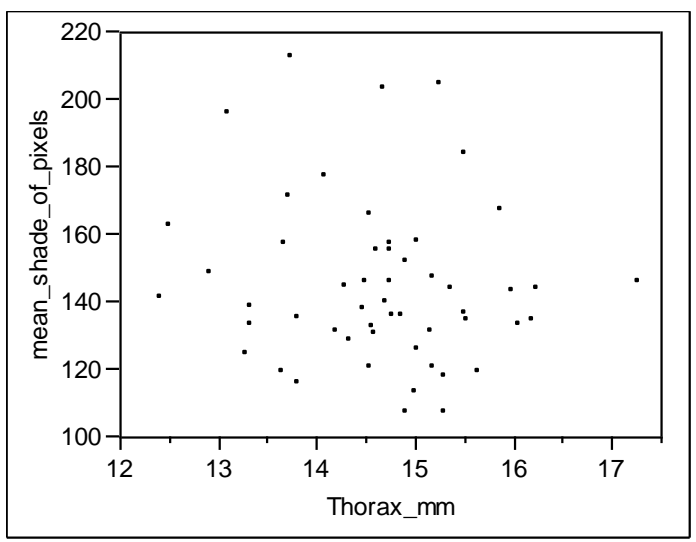

Figure 5. Site AA. Mean Shade by Thorax Size.

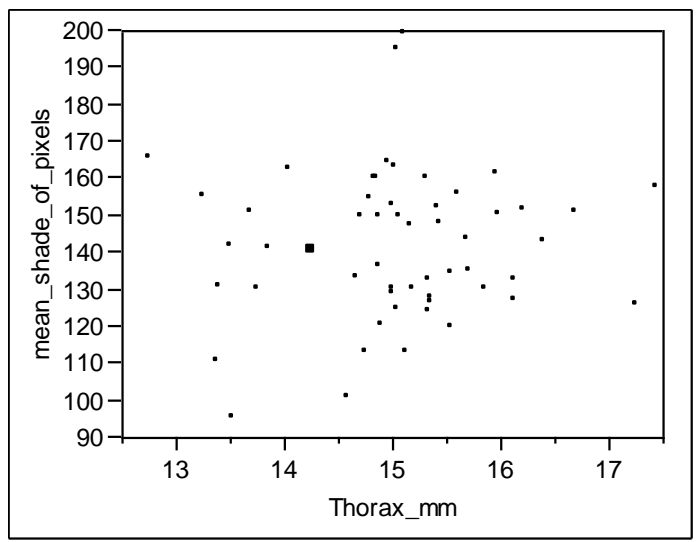

Figure 6. Site Airboat. Mean Shade by Thorax Size.

Immunocompetence is defined as the ability of an individual's immune system to resist and control pathogens or parasitoids [2]. Measuring the degree of encapsulation on a standard antigen (e.g., nylon fishing line) is one of the most commonly used ways of measuring immunocompetence [2]. Insect response to nylon line is remarkably similar to encapsulation response to parasites [3]. Haemocytes recognize foreign bodies (such as an abiotic fiber) and coat it to form a capsule, and the intruder dies from suffocation. Melanotic encapsulation is effective against multicellular organisms [4]. Even so, one of the reasons we saw no relationship between size and encapsulation might have been because we did not measure the appropriate immune trait. If we had measured some other immune function, we might have found a correlation between grasshopper size and immunocompetence.

Life history theory presumes immune function and other fitness constit- 


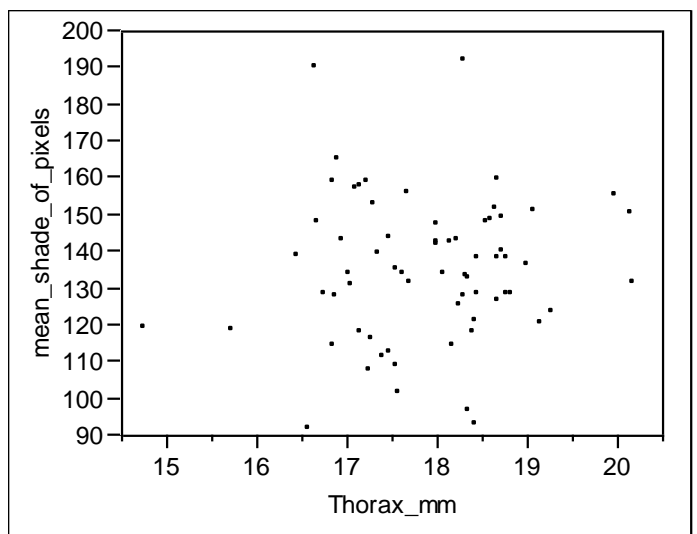

Figure 7. Site Casino. Mean Shade by Thorax Size.

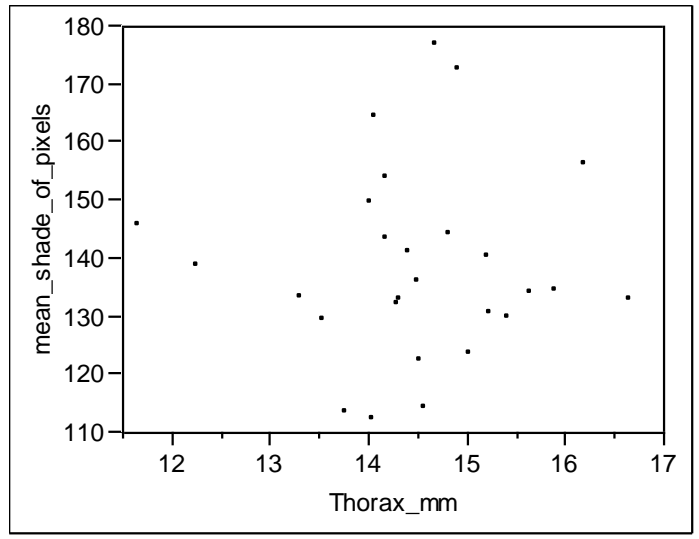

Figure 8. Site FX. Mean Shade by Thorax Size.

uents are traded-off against each other [5]. Two traits cannot work at maximum potential because an organism has a limited amount of energy; therefore, an increase in one trait often decreases the efficiency of the other. For example, when the bumble bee increases foraging, it loses immune efficiency because more energy is focused on foraging [6]. Many studies in Drosophila have found a numerous cost for immunocompetence. Drosophila have been found to have smaller female size and fecundity, lower competitive ability, and reduced resistance to starvation [7-11]. In crickets, encapsulation rate was negatively correlated to body size and development time [2]. While many other trade-offs between immune function and life history traits are known and widely studied, bodysize and it's trade-off with immunocompetence is not well understood. Future work needs to be directed at understanding what components of insect immunity are

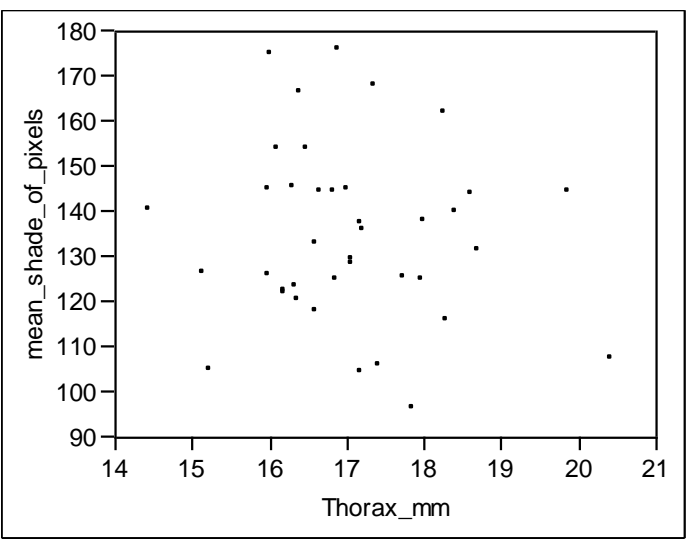

Figure 9. Site SVS. Mean Shade by Thorax Size.

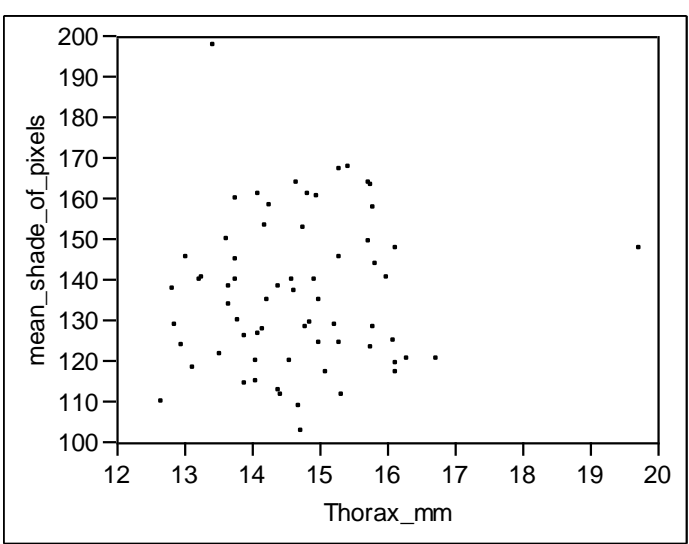

Figure 10. Site TL. Mean Shade by Thorax Size.

correlated with body size, what are the consequences of size-immunity correlations, and how might different environments select for correlations between body size and immunity.

\section{ACKNOWLEDGEMENT}

This research supported by NSF Grant No: A0633335

\section{REFERENCE}

1. Huizenga, K. M.,M. D. Shaidle, J.S. Brinton, L.A. Gore, M.A Ebo, A.J. Solliday, P.J. Buguey, D.W. Whitman, \& S.A. Juliano. "Geographic differences in the body sizes of adult Romalea microptera," Journal of Orthoptera Research (2008-in press).

2. Rantala $M$, Kortet $R$, "Courtship song and immune function in the field cricket Gryllus bimaculatus," Biological Journal 
of the Linnean Society 79 (2003) pp 503-510.

3. S. Paskewitz and M.A. Riehle, "Response on Plasmodium refractory and susceptible strains of Anopheles gambiae to inoculated sephadex beads," Developmental and Comparative Immunology 18 (1994), pp. 369-375.

4. Gillespie, JP, Kanost, MR, Trenczek, T, "Biological mediators of insect immunity" Annual Rev. Entomol, 42 (1997) pp 611 643.

5. Rantala M, Roff D, "An analysis of tradeoffs in immune function, body size and development time in the Mediterranean Field Cricket, Gryllus bimaculatus," Functional Ecology 19 (2005) pp 323330.

6. König C, Schimd-Hempel P, (1995) Foraging Activity and immunocompetence in workers of the bumble bee, Bombus terrestris. Proceedings of the Royal Society of London B 260: 225-227.

7. Fellowes M, Kraaijeveld A, Godfray $H$, "Trade-offs associated with selection for increased ability to resist parasitoid attack in Drosophila melanogater," Proceedings of the Royal Society of London B265 (1998) pp 1553-1558.

8. Fellowes M, Masnatta P, Kraaijeveld A, "Pupal parasitoids attack influences the relative fitness of Drosophila that have encapsulated larval parasitoids," Ecological Entomology 23 (1998) pp 281-284.

9. Fellowes M, Kraaijeveld A, Godfray H "Association between feeding rate and parasitoid resistance in Drosophila melanogater," Evolution 53 (1999) pp 1302-1305.

10. Fellowes M, Kraaijeveld A, Godfray H, "The relative fitness of Drosophila melanogater (Diptera, Drosophilidae) that have successfully defended themselves against the parasitoid Asobara tabida (Hymenoptera, Braconidae)," Journal of Evolutionary Biology 12 (1999) pp 123-128.

11. Fellowes $M$, \& Godfray, $H$, "Evolutionary ecology of resistance to parasitoids by Drosophila," Heredity 84 (2000) pp 1-8.

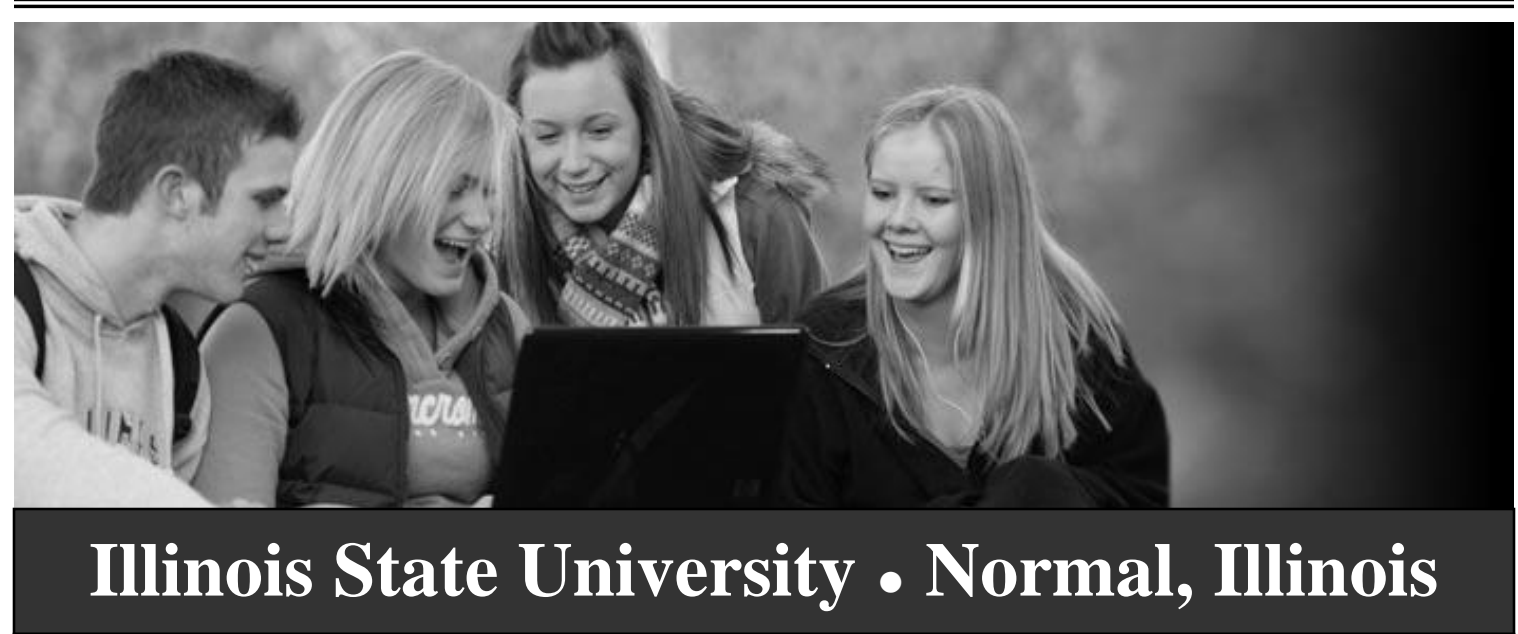

Founded in 1857, Illinois State University was the first public university in the state and one of the Midwest's oldest institutions of higher education. It is a residential university whose emphasis is on undergraduate study. Its 34 academic departments in six colleges offer 67 undergraduate programs in more than 188 fields of study. The Graduate School coordinates 39 master's, two specialist, and eight doctoral programs. 